\title{
ÁREAS DE PRESERVAÇÃO PERMANENTE E RESERVA LEGAL: PERCEPÇÃO DOS PROPRIETÁRIOS RURAIS DO MUNICÍPIO DE OTACÍLIO COSTA, SC
}

\author{
Carlos José Mendes ${ }^{1}$, Cíntia Urbano Neves ${ }^{2}$, Ricardo Berger ${ }^{3}$ \\ ${ }^{1}$ Eng. Florestal, M.Sc., Klabin Florestal, Telêmaco Borba, PR, Brasil - cjmendes@klabin.com.br \\ ${ }^{2}$ Eng $^{\mathrm{a}}$ Agrônoma, Klabin Florestal, Telêmaco Borba, PR, Brasil - cneves@ klabin.com.br \\ ${ }^{3}$ Eng. Florestal, Dr., Depto. de Economia Rural e Extensão, Curitiba, PR, Brasil - berger@ bsi.com.br \\ Recebido para publicação: 12/04/2010 - Aceito para publicação: 30/10/2012
}

\begin{abstract}
Resumo
A Reserva Legal Florestal é a área de conservação obrigatória dentro de uma propriedade rural, estabelecida pelo código florestal, a fim de manter a sustentabilidade dos recursos naturais. A preocupação em garantir grande parte das florestas intactas vem crescendo à medida que aumenta a perda de biodiversidade. O presente trabalho avaliou a visão dos proprietários frente ao conhecimento da legislação florestal, em particular a lei 4.771, de 15/09/1965 (Código Florestal), e a lei 11.428, de 22/12/2006, que tratam da Reserva Legal Florestal. Os dados foram obtidos através da aplicação de questionários aos produtores rurais no município de Otacílio Costa (SC). A interpretação dos resultados indica que os proprietários rurais têm pouco conhecimento sobre legislação e que a grande maioria (75\%) das propriedades apresenta-se irregular quanto à adequação da Reserva Legal. Para a difusão do conhecimento técnico e da legislação florestal ambiental, é recomendado o desenvolvimento de políticas públicas por órgãos competentes e de programas pelas empresas de base florestal atuantes na região, levados aos proprietários sob a forma de capacitação, assistência técnica e desenvolvimento, através dos programas de fomento florestal e de extensão rural.

Palavras-chave: Legislação florestal; legislação ambiental; propriedade rural.
\end{abstract}

\begin{abstract}
Permanent Preservation Areas and Legal Reserve: perception of land owners from the rural city of Otacílio Costa, SC. The Legal Forest Reserve is a required conservation area for rural properties, established by the Brazilian forest code in order to keep the sustainability of the natural resources. The worries about keeping large part of the forests untouched are increasing at the same time that environmental resources decrease. Therefore, the present work dealt with the evaluation of the landowner's vision, their knowledge about Brazilian forest legislation, which includes the Legal Forest Reserve regulation. The data were collected based on questionnaires applied to the landowners in Otacílio Costa city, Santa Catarina State. The results points to landowners' short knowledge about legislation as well as any sort of irregularities in $75 \%$ of their properties according to the Brazilian forest code. In order to spread information about forest technology and environmental forests law it is recommended the implementation of government policies by public institutions and private companies. Those policies need to be transferred to land owners by training sections and technical assistance and development involving tree farm programs and extension.

Keywords: Legal Forest Reserve; environmental legislation; rural property.
\end{abstract}

\section{INTRODUÇÃO}

A função social da propriedade rural estabelecida pelo estatuto da terra (Lei 4.504/64) condiciona o exercício do direito de propriedade ao cumprimento das seguintes obrigações: favorecer o bem-estar dos que na terra labutam, manter níveis satisfatórios de produtividade, assegurar a conservação dos recursos naturais e observar as disposições legais que regulam as justas relações de trabalho entre os que possuem o domínio e aqueles que cultivam a propriedade (MORAES, 1999).

O Código Florestal (Lei 4.771, de 15/09/1965) estabelece Áreas de Preservação Permanente (APP): aquelas localizadas ao redor de lagoas e lagos e ao longo dos rios, variando de acordo com a 
largura de cada um; nos topos de morro; nas encostas; nas nascentes, num raio mínimo de 50 metros; nas restingas e manguezais; nas bordas de tabuleiro; e nas chapadas e terrenos com declividade acima de 45 graus (COSTA; ARAÚJO, 2002a).

O conceito de APP está relacionado com a proteção de áreas de maior risco de degradação do ambiente, onde o manejo incorreto da vegetação existente pode ocasionar erosão, deslizamento de terra, assoreamento de rios e córregos e depreciação do valor das terras, entre outros (COSTA; ARAÚJO, 2002b).

De acordo com o Código Florestal Brasileiro (Lei ${ }^{\circ} 4.771$, de 1965), artigo $1^{\circ}$, $\S 2^{\circ}$, inciso III, Reserva Legal é "área localizada no interior de uma propriedade ou posse rural, excetuada a de preservação permanente, necessária ao uso sustentável dos recursos naturais, à conservação e reabilitação dos processos ecológicos, à conservação da biodiversidade e ao abrigo e proteção de fauna e flora nativas".

Bacha (2005a) ressalta as mudanças que surgiram ao longo do tempo na concepção pública sobre a RL, quando ela passou de uma reserva de madeira para uma área onde deve ser praticada a exploração sustentável dos recursos vegetais e florestais. No entanto, o grau de cumprimento da legislação sobre a RL é ainda relativamente muito pequeno no Brasil.

Segundo Abreu e Silva (2003), até 28 de maio de 2000, a Reserva Legal no Brasil constituía-se em uma reserva que literalmente tinha o objetivo de proteção das florestas e de outras formas de vegetação. Era uma reserva que propriamente poderia se chamar de reserva florestal, cujo objetivo maior era preservar as matas brasileiras ainda existentes. A partir de então, a RL deixou de ser reserva florestal para se tornar a área dentro do imóvel destinada à sustentabilidade dos recursos naturais, incorporando o conceito atual.

A Lei 11.428 , de 22/12/2006, poderá trazer benefícios aos pequenos proprietários rurais, visto que, no seu artigo $3^{\circ}$, inciso I, considera pequeno produtor rural aquele que detenha a posse de gleba rural não superior a 50 hectares. Isso reflete em flexibilidade nesse tipo de propriedade, para composição da RL. Por outro lado, aqueles que possuem propriedades maiores que 50 ha continuam com os problemas de recomposição da RL e deverão encontrar formas para sua adequação.

Para Padilha Júnior (2004), a inclusão da RL Florestal no contexto da propriedade rural introduz mais uma fonte de análise aos proprietários, no intuito de produzir alternativas para evitar a redução de renda.

Desse modo, torna-se importante conhecer como os impactos econômicos, ambientais e sociais com a adequação da RL são percebidos pelos proprietários rurais diretamente afetados por essa legislação e quais alternativas são propostas para essa adequação.

Nesse contexto, e para responder a essas questões, torna-se necessário desenvolver uma metodologia que permita caracterizar o agricultor e a propriedade frente aos critérios de desenvolvimento da atividade que lhes são impostos, facultando a identificação dos pontos positivos e de estrangulamento, referentes a aspectos sociais, econômicos e ambientais, de modo a possibilitar a proposição de soluções aos problemas encontrados.

Este trabalho tem por objetivo avaliar a percepção dos proprietários rurais com relação à Lei 4.771, de 15/09/1965 (Código Florestal), sobre as Âreas de Preservação Permanente e de Reserva Legal.

\section{MATERIAL E MÉTODOS}

\section{Localização da região de estudo}

O estudo foi desenvolvido no município de Otacílio Costa, localizado na região do planalto serrano sul-catarinense. O município vem constantemente se destacando no setor florestal devido à sua grande vocação florestal, evidenciada pelas extensas áreas reflorestadas, principalmente pelo gênero Pinus (UNIVERSIDADE FEDERAL DO PARANÁ, (UFPR) 2006), e se caracteriza pela expansão dos reflorestamentos de empresas que utilizam a madeira, tais como as serrarias, laminadoras, termoelétricas e de papel e celulose.

\section{Coleta de dados}

$\mathrm{Na}$ entrevista de campo, foram levantadas as características dos proprietários e das propriedades rurais, aspectos relacionados à legislação ambiental florestal, tanto daquela que trata de APP como da que trata da RL, bem como questões relativas à presença de reflorestamento na propriedade. 
Segundo a Comissão Estadual de Planejamento Agrícola (ICEPA, 2005), o município tem 343 propriedades rurais. Foram realizadas entrevistas de campo diretamente com os proprietários rurais, em sessenta propriedades rurais distribuídas em todo o município, sendo que a intensidade de amostragem foi de $17,5 \%$ do total das propriedades.

A pesquisa de campo foi realizada com o objetivo de determinar a percepção dos proprietários rurais em relação à RL, no que diz respeito ao conhecimento da legislação, à obrigatoriedade do cumprimento, à existência, manutenção e aumento, à sua importância e aos benefícios percebidos.

\section{Métodos de análise}

Os dados obtidos nas entrevistas foram calculados pelo primeiro autor e analisados utilizando-se de estatísticas descritivas, tais como proporções, médias e estimativas: -análise dos dados individualmente, de acordo com a coleta de campo. -análise de interações entre as questões correlacionadas.

\section{RESULTADOS E DISCUSSÃO}

\section{Caracterização dos proprietários}

Os resultados sobre o grau de escolaridade dos proprietários rurais mostram que $62 \%$ possuem o $1^{\circ}$ grau incompleto, $20 \%$ o $1^{\circ}$ grau completo, $8 \%$ o $2^{\circ}$ grau completo e $10 \%$ nunca estudaram. Os dados apresentam uma nova realidade para os produtores rurais, pois a grande maioria (90\%) possui algum grau de escolaridade e uma boa parcela (28\%) tem o ensino fundamental e médio completos.

A experiência regional leva a crer que essa grande parcela de proprietários que possuem o ensino fundamental incompleto é constituída por aqueles que frequentaram a escola para o aprendizado básico, ou seja, aprenderam a ler, escrever e "fazer contas", para logo em seguida deixar a escola e ajudar nas atividades rurais.

Os dados pesquisados mostram que a grande maioria dos proprietários rurais $(93 \%)$ reside na propriedade e que metade dos proprietários (56\%) está com idade superior a 50 anos, mostrando a pouca participação da população jovem nas propriedades rurais, ficando para a camada de maior idade permanecer na terra.

\section{Propriedades rurais}

A predominância de propriedades com áreas até 50 ha (65\%), que é característica da pequena propriedade rural, deve-se, provavelmente, ao desmembramento ou partilha de herança.

Entre aquelas propriedades visitadas com área maior que 50 ha, a de maior tamanho encontrada foi de 560 há, e o tamanho médio foi de 69 ha, ressaltando o perfil fundiário de pequenas propriedades na região.

A tabela 1 apresenta as formas de utilização em percentagem por classe de áreas.

Tabela 1. Interação entre as classes de tamanho da propriedade e a forma de utilização (atividades).

Table 1. Interaction between the land class size use (activities).

\begin{tabular}{lcccc}
\hline Atividade & $\mathbf{5}$ ha & $\mathbf{6 - 3 5}$ ha & $\mathbf{3 6 - 5 0}$ ha & $\mathbf{2 5 0}$ ha \\
\hline Lavouras temporárias & $19 \%$ & $24 \%$ & $10 \%$ & $10 \%$ \\
Pastagens naturais & $21 \%$ & $26 \%$ & $36 \%$ & $38 \%$ \\
Pastagens plantadas & $17 \%$ & $9 \%$ & $9 \%$ & $4 \%$ \\
Florestas naturais & $17 \%$ & $23 \%$ & $36 \%$ & $34 \%$ \\
Florestas plantadas & $11 \%$ & $13 \%$ & $6 \%$ & $12 \%$ \\
Benfeitorias & $15 \%$ & $4 \%$ & $4 \%$ & $1 \%$ \\
\hline Total & $100 \%$ & $100 \%$ & $100 \%$ & $100 \%$ \\
\hline
\end{tabular}

Existe uma tendência de aumento de florestas naturais com o aumento da área da propriedade, mas um fato que preocupa é o baixo percentual destas nas pequenas propriedades, caracterizadas por áreas abaixo de 50 ha.

As pequenas propriedades têm, percentualmente, uma área maior usada por pastagens plantadas, por certo devido à necessidade de cultivo intensivo e à pouca quantidade de terra disponível. 
Também a área ocupada por benfeitorias tem maior influência nas pequenas propriedades, pois seu efeito é percentualmente alto.

A utilização da terra para fins agropecuários, isto é, lavouras temporárias, pastagens naturais e plantadas, tem presença marcante e sempre acima de 50\% da área da propriedade, por certo buscando-se culturas para subsistência, bem como para venda do excedente.

\section{Caracterização dos proprietários em face da legislação florestal}

Foram levantadas informações junto aos proprietários rurais com relação à legislação ambiental florestal, sendo que $45 \%$ dos produtores responderam que conhecem alguma legislação ambiental florestal e 55\% não.

Aqueles que responderam conhecer a legislação ambiental florestal (45\%), em questão aberta, foram perguntados sobre o que ela permite e o que ela proíbe. Nas respostas sobre o que permite, $78 \%$ responderam "respeitar as águas e matas" e $22 \%$ "respeitar somente áreas de preservação (RL e APP)". Nas respostas sobre o que proíbe, $84 \%$ responderam o desmatamento, $8 \%$ responderam que poluição ambiental e das águas e $8 \%$ "usufruir da área", sendo citado que proíbe usufruir da área e proíbe a retirada do pinheiro (Araucaria angustifolia).

A interação entre a escolaridade dos proprietários e o recebimento de informações sobre legislação ambiental florestal mostra que os percentuais de recebimento de informações são baixos, variando entre 20 e 33\%, revelando que a informação que está chegando ao campo é muito pouca e independe do grau de escolaridade.

Entre todos os entrevistados, $25 \%$ responderam que já receberam informações sobre leis ambientais, e 75\% não receberam informações.

Observou-se que $93 \%$ dos proprietários entrevistados nunca receberam fiscalização sobre temas ambientais e, dentre os que foram fiscalizados, (7\%) foram notificados, mas não pagaram multas e nem realizaram planos de recuperação ambiental.

\section{Percepção dos proprietários rurais em relação à legislação de APP}

Após a explanação de informações básicas sobre Áreas de Preservação Permanente, 98\% dos proprietários afirmaram que aplicam as leis na sua propriedade.

Na figura 1 são apresentados os dados relacionados à totalidade dos entrevistados, em relação ao motivo por que o produtor protege as áreas de APP.

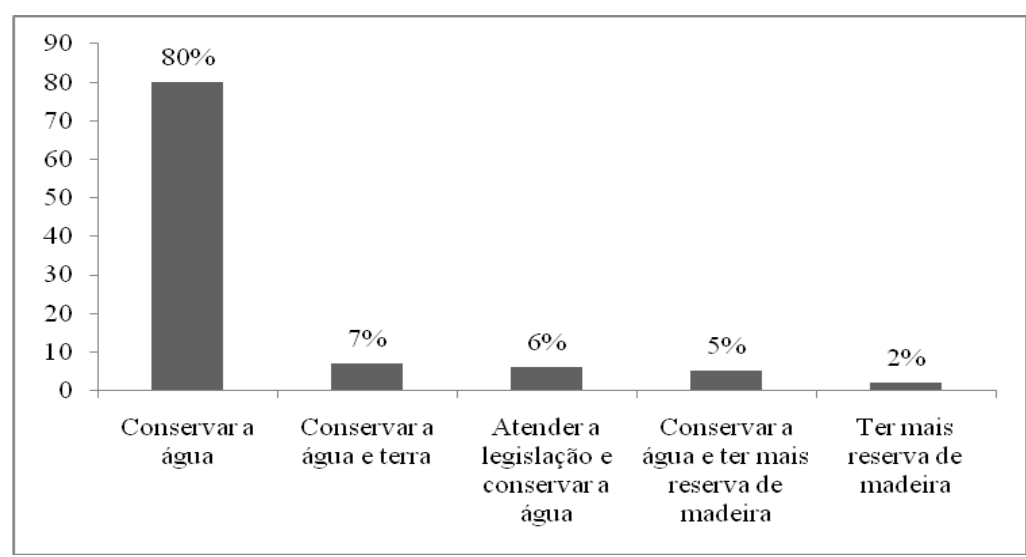

Figura 1. Percentual das respostas do motivo por que o produtor protege as APP.

Figure 1. Percentage of answers for the reasons presented by the producers to protect the APP's.

Observou-se que $80 \%$ responderam para conservar as águas, $7 \%$ para conservar a água e a terra, $6 \%$ para atender a legislação, $5 \%$ para conservar a água e ter mais reserva de madeira e $2 \%$ para ter mais reserva de madeira.

Em uma síntese da análise da visão dos proprietários rurais em relação à legislação de APP, verifica-se que: 
a) com relação à opinião sobre a lei de APP, os proprietários estão fortemente convictos sobre a questão de conservação das águas, no que diz respeito à qualidade da água, à conservação das nascentes, das margens de rios e lagos e a preservação das encostas;

b) para a grande maioria dos proprietários, proteger as APP é importante para conservar as águas, para atender à legislação e para ter mais reserva de madeira. Esta última informação mostra certa confusão entre APP e Reserva Legal (RL), visto que a utilização de madeira (relatada como reserva de madeira) só é possível em áreas de RL;

c) para melhorar as áreas de APP nas suas propriedades, os proprietários têm realizado atividades, como: evitar o desmatamento, no que diz respeito a preservar as matas, conservar as matas ciliares e proteger as nascentes; proteger as águas; evitar atividades na APP, impedindo a entrada de animais; fazer plantio de árvores em volta das nascentes e onde não há mata ciliar.

\section{Percepção dos proprietários rurais em relação à legislação de Reserva Legal}

Após explanação da legislação sobre RL e com base em sua visão, $95 \%$ dos produtores entrevistados responderam que têm RL na propriedade.

$\mathrm{Na}$ figura 2 estão as respostas do motivo por que o produtor tem RL na propriedade.

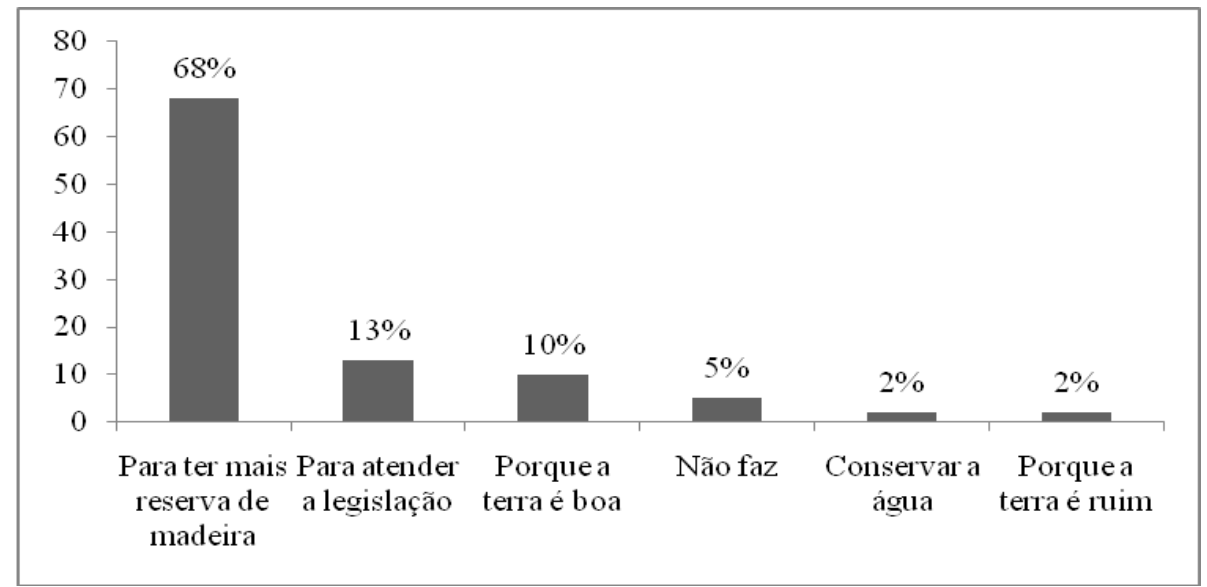

Figura 2. Razões para a manutenção da RL na propriedade rural.

Figure 2. Reasons for maintenance of the legal reserve in rural property.

Na opinião de $68 \%$ dos proprietários, a manutenção da RL é para ter mais reserva de madeira; na de $13 \%$, para atender à legislação; na de $10 \%$, porque a terra é boa; na de $2 \%$, para conservar água; na de $2 \%$, porque a terra é ruim; e $5 \%$ declararam que não têm RL. Dentre aqueles que declararam que é pelo motivo de que a terra é ruim, a alternativa está em, provavelmente, deixar esse tipo de terra para "crescer mato".

Na visão dos proprietários, 93\% dos seus vizinhos seguem a legislação que trata da RL.

Os dados revelam que somente $27 \%$ dos proprietários aumentaram as áreas de RL nos últimos 10 anos.

Não existe correlação entre aqueles que aumentaram a área de conservação e a existência de reflorestamento na sua área, evidenciando que a presença de reflorestamento na propriedade não motivou os proprietários a aumentar a área de RL. Parte dessa indecisão deve-se à baixa assistência técnica e à pouca informação que chega ao campo.

Segundo a pesquisa, 78\% dos entrevistados pretendem aumentar as áreas de RL na propriedade, sugerindo uma tendência de melhoria nas áreas de conservação, 48,0\% responderam que deixam de usar áreas produtivas e $22,5 \%$ relatam a preocupação com a manutenção de áreas de conservação em pequenas propriedades.

Os dados da interação sobre a intenção dos proprietários que pretendem aumentar áreas de RL e o recebimento de informações sobre legislação ambiental florestal mostram que, entre aqueles que não 
pretendem aumentar as áreas de RL, 24\% não recebem informações sobre a legislação ambiental florestal e 76\% responderam que recebem informação. Entre aqueles que pretendem aumentar as áreas, $13 \%$ não recebem informações, enquanto que $87 \%$ responderam que sim. As informações mostram que não há uma correlação entre essas duas características.

A interação entre os proprietários que pretendem aumentar áreas de RL e o recebimento de assistência técnica revela que, entre aqueles que não pretendem aumentar áreas de RL, $62 \%$ não recebem assistência técnica, e 38\% recebem. Entre aqueles que pretendem aumentar áreas de RL, $45 \%$ não recebem assistência técnica e 55\% recebem.

As informações mostram uma correlação positiva entre a assistência técnica e a intenção em aumentar áreas de conservação, em vista de os dados estarem polarizados, potencializando não/não e $\mathrm{sim} / \mathrm{sim}$, isto é, quando os proprietários não pretendem e não recebem assistência e quando pretendem e recebem assistência.

A informação é importante, particularmente com a mudança da legislação (Lei 11.428, de 22/12/2006), e melhorou significativamente as condições de recomposição da RL, tendo em vista que pode ser implementada com reflorestamento, proporcionando renda à área e recompondo a rentabilidade da propriedade.

Entre os proprietários que pretendem aumentar as áreas de florestas para conservação, 53\% possuem áreas reflorestadas e $47 \%$ não. Entre os proprietários que não pretendem aumentar as áreas de conservação, $69 \%$ possuem áreas reflorestadas e $31 \%$ não. Isso mostra que o produtor detentor de floresta está interessado na produção e, consequentemente, na renda, e não em áreas de conservação.

A tabela 2 demonstra que tipo de área o produtor tem intenção de conduzir para aumentar a RL.

Tabela 2. Áreas que os proprietários destinam para aumentar a RL, em \%.

Table 2. Areas that owners designate to increase the Legal Reserve in $\%$.

\begin{tabular}{lc}
\hline Áreas destinadas à manutenção da RL & $\%$ \\
\hline Nas faixas dos rios & 56 \\
Em encostas & 42 \\
Em áreas não produtivas & 2 \\
\hline Total & 100 \\
\hline
\end{tabular}

Entre os proprietários que declaram que pretendem aumentar essas áreas $(78 \%$ do total entrevistado), $56 \%$ declararam nas faixas dos rios; $42 \%$ em encostas e $2 \%$ em áreas não produtivas. $\mathrm{O}$ grande percentual das respostas (56\%) nas faixas dos rios mostra a dificuldade dos produtores em separar as questões de APP e RL.

Como intenção dos proprietários em aumentar as áreas de RL nas suas propriedades, 96\% responderam para obtenção de autorização de corte e $4 \%$ para averbação em cartório. Isso mostra que os produtores não estão interessados em conservação e, sim, em regularizar autorização de corte.

Tabela 3. Método que os produtores utilizarão para aumentar as áreas de RL, em \%.

Table 3. Method that producers intend to use in order to increase areas of Legal reserve in \%.

\begin{tabular}{lc}
\hline Respostas & $\%$ \\
\hline Deixando o mato crescer (regenerar) & 66 \\
Plantando & 34 \\
\hline Total & 100 \\
\hline
\end{tabular}

Entre os que declaram que pretendem aumentar essas áreas, quando perguntados sobre quais métodos usarão, $66 \%$ declararam que deixarão o mato crescer (regenerar), e $34 \%$ plantando árvores nativas.

Embora possa existir grande variabilidade na forma de recompor a RL dentro dos diferentes biomas, pode-se inferir que o custo operacional (valores estimados para os três primeiros anos) deverá ficar entre $\mathrm{R} \$ 3.000,00$ e $\mathrm{R} \$ 4.000,00$ por hectare. A maior parte desses gastos concentra-se no custo da mão de obra e no custo das mudas de essências nativas (BERGER; PADILHA JÚNIOR, 2006).

A partir desses dados, pode-se inferir que os produtores rurais citam que fariam a recomposição da RL plantando, mas provavelmente desconhecem o montante a ser gasto no plantio das árvores nativas, 
já que os custos para implantação de reflorestamento são bem menores que estes. Os custos de implantação de reflorestamento são menores porque exigem menor número de tratos culturais, técnicas de plantio sistematizadas e uso de agroquímicos, que normalmente não são permitidos em plantios de áreas de APP e RL.

Os dados mostram que os produtores têm pouca disposição de usar recursos próprios para manter as áreas de conservação e que esperam que "outros" resolvam a sua situação de descumprimento da legislação. Esse é um fato comum entre os proprietários e empreendedores rurais da região, de deixar as resoluções de pendências legais "para depois" ou aguardar que nova lei venha mudar a que está em vigor.

Em uma síntese da percepção dos proprietários rurais em relação à legislação de RL, observa-se que:

a) a opinião dos proprietários rurais sobre a legislação que trata da RL é que deve ser respeitada e preservada, para melhorar o equilíbrio ambiental e para ter mais reserva de madeira. Como desvantagens, deixam de usar áreas produtivas e os proprietários de pequenas propriedades terão problemas para se manter, de modo que o governo deveria dar alguma ajuda a eles;

b) os proprietários que aumentaram as suas áreas de conservação nos últimos 10 anos ainda pretendem aumentar suas áreas de floresta plantada e gostariam de receber mais assistência técnica, independentemente do grau de escolaridade desses proprietários;

c) não há uma correlação entre os proprietários que aumentaram as áreas de floresta nos últimos 10 anos, os que pretendem aumentar áreas de floresta e o tamanho das suas propriedades;

d) existe uma correlação positiva entre os proprietários que pretendem aumentar áreas de RL e o recebimento de informações sobre legislação ambiental florestal;

e) existe uma correlação positiva entre os proprietários que aumentaram as áreas de RL nos últimos 10 anos e aqueles que pretendem aumentar as áreas de RL, fazendo-se necessário que programas de difusão de informações sejam melhor implementados, para reverter a intenção dos que não aumentaram área de conservação e pretendem aumentar;

f) há certa dificuldade ou confusão dos proprietários rurais em separar as questões de APP e RL, em vista de alto percentual de resposta de implementar as áreas nas faixas dos rios, para aumentar a RL.

\section{Percepção dos proprietários rurais em relação à legislação ambiental em conjunto de APP e RL}

RODRIGUES et al. (2006) desenvolveram trabalho de compilação de dados de 29 projetos de adequação ambiental de 1.401 propriedades, realizados pela Universidade de São Paulo - Escola Superior de Agricultura "Luiz de Queiroz" - Laboratório de Ecologia e Restauração Florestal (LERF), no período de 2000 a 2006, totalizando 452.732,50 ha, no estado de São Paulo. O autor cita que as APP representam cerca de $10 \%$ da área das propriedades e que os fragmentos fora da APP, considerados como área de Reserva Legal, representam cerca de 5\% da área total da propriedade, cerca de $2 \%$ de áreas com baixa aptidão agrícola e 0,5\% de áreas agrícolas que deveriam ser convertidas em corredores ecológicos de $60 \mathrm{~m}$ de largura, para permitir a interligação à APP dos fragmentos florestais remanescentes ocorrentes fora da APP.

Tomando como base esse dado de APP na propriedade rural (10\%) e analisando conjuntamente a composição total de APP mais RL, o valor a ser encontrado nas propriedades deverá ser de $30 \%$, o suficiente para atender a legislação.

A figura 3 mostra que $75 \%$ das propriedades possuem percentual menor que $30 \%$ na soma de APP e RL e que somente $25 \%$ das propriedades possuem o percentual maior que $30 \%$, suficiente para cumprir a legislação.

Como já citado anteriormente, mais de $90 \%$ dos proprietários declararam que seguem a legislação que trata das áreas de RL, mas os dados coletados na pesquisa de campo que estão na figura 3 indicam que $75 \%$ das propriedades não possuem áreas de APP+RL suficientes. Esses dados sugerem que os proprietários têm pouca informação sobre a RL.

Os dados coletados na pesquisa de campo mostram que os proprietários mais jovens já procuram regularizar sua propriedade à realidade da legislação ambiental florestal, e que existe uma tendência de elevação do percentual de área total de APP e RL conforme o aumento da idade dos proprietários, a partir da idade de 30 anos. 


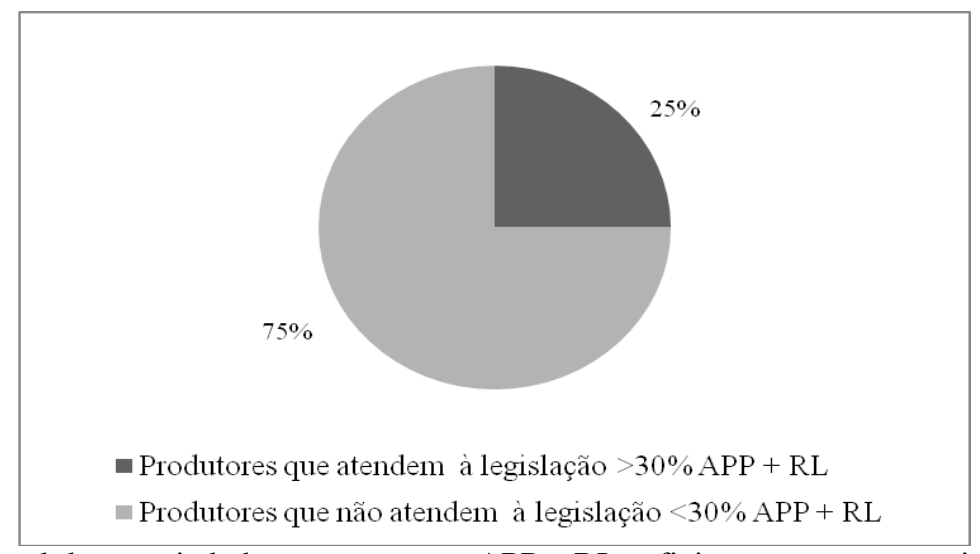

Figura 3. Percentual de propriedades que possuem APP e RL suficientes para composição total de $30 \%$.

Figure 3. Percentage of properties that present APP and Legal Reserve enough to the total composition of $30 \%$.

$\mathrm{Na}$ interação entre o tamanho da propriedade e a área total de APP e RL na propriedade, os dados mostram que:

a) nas propriedades com até 5 ha, nenhuma possui área suficiente para cumprir a legislação; com a lei;

b) nas propriedades com área entre 6-35 ha, 23\% possuem áreas de APP e RL em conformidade

c) nas propriedades com área entre $36-50$ ha, $50 \%$ possuem áreas de APP e RL em conformidade com a lei; com a lei.

d) nas propriedades com área maior que 50 ha, 29\% possuem áreas de APP e RL em conformidade

As informações aqui constantes levam a uma grande preocupação com as pequenas propriedades, em vista do baixo cumprimento da legislação. A mudança na legislação com a edição da lei 11.428 , de 22 de dezembro de 2006, que alterou a área da pequena propriedade rural para 50 ha, vem contribuir para o atendimento da legislação ambiental, já que nessas propriedades podem ser computados os plantios de árvores frutíferas ornamentais ou industriais, compostos por espécies exóticas, cultivadas em sistema intercalar ou em consórcio com espécies nativas, para o cumprimento da obrigatoriedade da RL.

Notou-se também que mesmo aqueles que possuem propriedades maiores que 50 ha ainda não se adequaram à legislação. Os dados da pesquisa de campo de compra de terra nos últimos 15 anos mostram que $33 \%$ dos proprietários o fizeram indicando que as propriedades são "velhas", ou seja, estão com os proprietários ou familiares há bastante tempo, sugerindo que estes não se adequaram à legislação porque não tiveram a necessidade de "mexer" na matrícula do imóvel, pois quando o fizerem, haverá obrigatoriedade de averbação da RL, por conseguinte, da recomposição ou reconstituição desta.

Verificou-se que, entre as propriedades que têm menos que 30\% da área total em APP e RL, $49 \%$ recebem assistência técnica e 51\% não recebem. Já entre aquelas que têm área total de APP e RL maior que $30 \%$ na propriedade, $59 \%$ recebem assistência técnica e $41 \%$ não recebem.

Os dados da interação entre os proprietários que receberam informações sobre a legislação que trata de APP e RL e o percentual de área destas (APP e RL) na propriedade mostram que mais informações precisam chegar até os proprietários rurais e que isso tem reflexo na manutenção de áreas para composição das APP e RL na propriedade rural.

A discussão sobre a importância, regulamentação, controle e recomposição da RL, na prática, tem sido muito intensa no âmbito do legislativo, entidades governamentais e não governamentais, associações de classes e empresários. Políticas públicas devem ser implementadas para fazer chegar as informações àqueles que estão diretamente envolvidos com a questão e detêm a posse da propriedade rural.

Com relação à interação entre área total de APP e RL na propriedade e a intenção dos proprietários em aumentar as áreas de RL, observou-se que 80\% daqueles que têm área menor que 30\% 
responderam afirmativamente, e que 73\% daqueles que têm área maior que 30\% também responderam que sim. As respostas mostram que, independentemente de possuir ou não área suficiente de APP e RL, os proprietários têm interesse em aumentar as áreas de conservação.

Bacha (2005b) ressalta que, para a reposição da RL ser lucrativa ao produtor rural (pois ela terá que reduzir áreas produtivas), é necessário que a nova composição florística seja feita com espécies comerciais. Uma vez que estas sejam definidas, deve-se autorizar o seu plantio em florestas heterogêneas enriquecidas, onde há maior presença de espécies de valor comercial. Mas, para manter o aspecto de conservação ambiental da RL, podem-se sugerir dois procedimentos: (1) a RL deve, prioritariamente, surgir ao redor da Área de Preservação Permanente, servindo de área tampão a essa última; (2) a RL deve ser composta de maneira gradual, partindo de plantios mais homogêneos nas áreas próximas às lavouras e pecuária e aumentando sua heterogeneidade à medida que se aproxima das áreas de preservação permanente.

Independentemente de possuírem áreas de APP e RL suficientes para cumprir a legislação, os produtores têm pouca disposição de utilizar seus recursos para aumentar as áreas de conservação. Uma grande parte ainda não sabe de que recursos poderá dispor para tal, reforçando a ideia de que estão esperando que "outros" resolvam sua situação de descumprimento frente à legislação ambiental e muitos acreditam que, recebendo as mudas, farão o plantio e se enquadrarão.

O desconhecimento dos produtores com relação aos custos de recomposição (plantio) pode levar a um fracasso desse modelo de recomposição.

Nos últimos anos, algumas possibilidades nesse sentido começaram a ser aventadas. A primeira delas é a compensação financeira aos proprietários pela manutenção de florestas protetoras dos recursos hídricos, com fundos provenientes da cobrança pelo uso da água.

Outra fonte de compensação discutida atualmente é o chamado mecanismo do desenvolvimento limpo (MDL), ao qual está vinculado o "mercado de carbono". De forma simplificada, o "mercado de carbono" aplicado à questão das reservas legais poderia funcionar da seguinte maneira: proprietários de terras dispostos a plantar florestas (que absorvem carbono em sua fase de crescimento) receberiam recursos provenientes de indústrias interessadas em manter ou aumentar seus níveis de emissão de gás carbônico em outras partes do mundo (VIANA et al., 2002).

O investimento em projetos para a negociação de créditos de carbono não é somente para as grandes companhias. O movimento ganha espaço entre os pequenos empresários. Algumas pequenas empresas de São Paulo já começaram a desenvolver projetos para gerar créditos de carbono, através da criação de mecanismos de desenvolvimento limpo (MDL).

Um exemplo dessa perspectiva foi a substituição de madeira nativa por resíduos de reflorestamento como fonte energética de uma pequena empresa. No início, a preocupação era apenas reduzir custos, mas isso acarretou uma redução bem mais elevada e uma melhoria da imagem da empresa.

Pequenas empresas possuem, muitas vezes, potencial para gerar créditos de carbono, mas não sabem como. A falta de acesso à informação sobre crédito de carbono ocasiona a perda da participação do Brasil no mercado mundial, com apenas 4\% do total negociado (O ESTADO DE SÃO PAULO, 2007).

Em uma síntese da análise da visão dos proprietários rurais em relação à legislação ambiental em conjunto de APP e RL, observa-se que:

a) das propriedades estudadas, somente $25 \%$ têm área de APP e RL suficiente para cumprir a legislação, e em casos extremos encontram-se as menores propriedades ( $<5 \mathrm{ha})$, visto que nenhuma delas possui área suficiente;

b) os proprietários têm pouco conhecimento sobre a RL florestal, pois $95 \%$ deles declaram que têm na sua propriedade, mas, no levantamento de campo, somente $25 \%$ dessas propriedades realmente a possuem;

c) existe uma falta de informação ou confusão para os proprietários rurais do que são áreas de preservação permanente (APP) e o que são áreas de RL, em vista do alto percentual de declaração de utilização de madeira em áreas de APP e recomposição de áreas de RL nas margens dos rios;

d) o baixo recebimento de informações sobre legislação (25\% dos proprietários) também contribuiu para a baixa percentagem de propriedades com RL e APP;

e) a edição da lei 11.428 , de 22/12/2006, que alterou a área da pequena propriedade rural para 50 ha, flexibiliza a implantação da RL nessas propriedades, em vista das suas características de composição da RL. Essa medida veio contribuir para o atendimento da legislação ambiental na região, em 
vista de que cerca de $65 \%$ das propriedades são menores que 50 ha. Também deve melhorar a renda dessas propriedades. Um ponto importante dessa mudança na legislação é que se podem utilizar florestas plantadas na recomposição da RL;

f) mais de $70 \%$ dos proprietários que não têm área suficiente para atender a legislação têm interesse em aumentar áreas de conservação;

g) o grau de escolaridade, a intenção de aumentar área de conservação e a forma como o produtor pretende aumentar as áreas de conservação não têm correlação com o potencial atual de áreas de APP e RL na propriedade;

h) a assistência técnica é baixa, tanto em áreas em que a APP e RL são maiores que $30 \%$ quanto naquelas em estão abaixo desse percentual.

\section{CONCLUSÕES}

- Os proprietários têm pouca informação sobre as áreas de conservação, representadas pela APP e RL, uma vez que mais da metade declarou que conhece a legislação da RL e que possui área suficiente para composição dessas áreas em suas propriedades, mas a realidade no campo é que menos de $30 \%$ realmente a possuem.

- Os dados apresentados permitem inferir que a maioria das propriedades rurais da região não se encontra em conformidade com o cumprimento da legislação referente à Reserva Legal florestal.

- Nas propriedades que não têm áreas suficientes para atender a legislação da RL, cerca de $70 \%$ dos proprietários rurais têm interesse em aumentar as áreas de conservação, mas a grande maioria tem intenção de fazê-lo através da regeneração natural. Quando a intenção de aumento é através de plantio, os proprietários têm pouca disposição para utilização de recursos próprios, aguardando que outras entidades ou empresas o façam.

- A redução da área produtiva das propriedades, decorrente do estabelecimento da RL florestal, poderá contribuir para a perda de escala das atividades rurais, com consequente diminuição de renda.

- Os proprietários rurais têm baixa escolaridade, pois mais de $60 \%$ tem o $1^{\circ}$ grau incompleto, o que, na experiência regional, representa aqueles que frequentaram a escola para aprendizado básico, ou seja, ler, escrever e fazer contas. Além disso, recebem pouca assistência técnica, particularmente os produtores de pequenas propriedades.

- A estrutura fundiária do município permite inferir que haverá uma tendência de concentração de terras no município, pois ela é constituída por pequenas propriedades rurais, a grande maioria dos proprietários das terras residem nelas e esses proprietários estão ficando com idade avançada.

- Políticas públicas devem ser desenvolvidas para viabilização da adequação das áreas de RL, cabendo às empresas, entidades de pesquisa, extensão e ensino e autarquias dos governos municipais e estaduais desenvolver e implementar programas de capacitação pessoal, treinamento e desenvolvimento florestal e ambiental.

- As políticas desenvolvidas devem ser levadas principalmente aos pequenos proprietários, no sentido de melhoria da organização da propriedade rural, da qualidade da água, do respeito à legislação ambiental e da melhor ocupação do solo.

- Estudos de geração de renda em áreas de RL, através da utilização de produtos florestais não madeiráveis e mercado de crédito de carbono, devem ser implementados, visando à manutenção da rentabilidade das propriedades e viabilizando a preservação e conservação do meio ambiente.

\section{REFERÊNCIAS}

ABREU e SILVA, M. de. Reserva Legal: novos aspectos conceituais e responsabilidade. Belo Horizonte: Federação da Agricultura e Pecuária do Estado de Minas Gerais, 2003.

BACHA, C. J. C. Eficácia da política de Reserva Legal no Brasil. In: WORKSHOP SOBRE RESERVA LEGAL: LEGISLAÇÃO, USO ECONÔMICO E IMPORTÃNCIA AMBIENTAL, 2, mar 2005, Piracicaba. Anais... Piracicaba, 2005 p. 1 - 16.

BERGER, R.; PADILHA JR., J. B. O impacto da Reserva Legal florestal sobre a agropecuária 
paranaense. Curitiba: FAEP/SENAR, 2006.

COSTA, R. D. G.; ARAÚJO, M. Planejando o uso da propriedade rural. Jornal Agora, Caderno do Meio Ambiente, $\mathrm{n}^{\circ}$ 8, Itabuna, abril de 2002.

INSTITUTO COMISSÃO ESTADUAL DE PLANEJAMENTO AGRÍCOLA (ICEPA). Boletins Informativos. Santa Catarina: ICEPA, 2004.

MORAES, L. C. de. Código Florestal comentado: com alterações da lei de crimes ambientais, Lei ${ }^{\circ}$ 9.605/98. São Paulo: Atlas, 1999.

O ESTADO DE SÃO PAULO. Pequenas também ganham com crédito de carbono. São Paulo, jul de 2007. Disponível em: <http://empresas.globo.com/Empresasenegocios/>. Acesso em: 10 de jul de 2007.

PADILHA JÚNIOR, J. B. O impacto da Reserva Legal Florestal sobre a agropecuária paranaense, em um ambiente de risco. 2004. 181 p. Tese (Doutorado em Ciências Florestais, Área de concentração Economia e Política Florestal) - Escola de Florestas, Universidade Federal do Paraná, Curitiba.

RODRIGUES, R. R.; GANDOLFI, S.; FERRAZ, S. F. B.; NAVE, A. G.; FERRAZ, K. M. P. M. B. Consolidação dos dados de adequação ambiental executados pelo Laboratório de Ecologia e Restauração Florestal (LERF) em áreas agrícolas do Estado de São Paulo: Diagnóstico das Áreas de Preservação Permanente e de Reserva Legal. Piracicaba: ESALQ-USP, Dez. 2006.

UNIVERSIDADE FEDERAL DO PARANÁ / LABORATÓRIO DE INVENTÁRIO FLORESTAL / FUNDAÇÃO HUGO SIMAS, UFPR/LIF/FHS. Diagnóstico da base florestal no raio de $150 \mathbf{~ k m ~ e m ~}$ torno do centro do município de Otacílio Costa. Curitiba, PR: UFPR/LIF/FHS. 2006, 38 p.

VIANA, V. M.; MAY, P.; LAGO, L.; DUBOIS, O.; GRIEG-GRAN, M. (2002). Instrumentos para o manejo sustentável do setor florestal privado no Brasil: uma análise das necessidades, desafios e oportunidades para o manejo de florestas naturais e plantações florestais de pequena escala. London: IIED - International Institute for Environment and Development. 2002, p. 104. 
